\title{
Analisis Rhodamin B pada Lipstik Impor yang Beredar di Kota Batam secara Kromatografi Lapis Tipis dan Spektrofotometri UV-Vis
}

\section{Analysis of Rhodamin B in Imported Lipstick at Batam City by Thin Layer Chromatography and UV-Vis Spectrophotometry}

\author{
Trie Yuni Elfasyari ${ }^{1 *}$, Mutia Amelia Putri ${ }^{1}$, Regina Andayani ${ }^{2}$ \\ ${ }^{1}$ Prodi Sarjana Farmasi STIKes Mitra Bunda Persada, \\ Jl. Raya Seraya Nomor No.1, Tlk. Tering, Kec. Batam Kota, \\ Kota Batam, Kepulauan Riau 29444, Indonesia \\ ${ }^{2}$ Fakultas Farmasi Universitas Andalas, \\ Limau Manis, Padang 25163, Indonesia \\ *Corresponding author email: trieyunielfasyari@mbp.ac.id
}

Available online 01-07-2020

\begin{abstract}
ABSTRAK
Zat warna rhodamin B adalah bahan pewarna yang dilarang penggunaannya dalam sediaan lipstik karena memiliki potensi karsinogenik dan merusak organ hati. Penelitian ini bertujuan untuk mengetahui secara kualitatif dan kuantitatif zat rhodamin B dalam sediaan lipstik impor yang beredar di Pasar Kota Batam. Metode yang digunakan adalah kromatografi lapis tipis untuk mengidentifikasi senyawa rhodamin $B$ dengan menghitung nilai Rf dari fluoresensi bercak di bawah sinar ultraviolet. Penentuan kadar rhodamin B dilakukan dengan alat spektrofotometer UV-visibel dengan mengukur absorban pada panjang gelombang maksimum $548,5 \mathrm{~nm}$. Konsentrasi larutan baku standar rhodamin $B$ adalah 0,$8 ; 1,2 ; 1,6 ; 2,0 ;$ dan $2,4 \mu \mathrm{g} / \mathrm{mL}$. Didapatkan persamaan kurva $\mathrm{y}=0,0128+0,276 \mathrm{x}$ dengan $r=0,9999$. Hasil analisis kualitatif dari 15 merek sampel lipstik didapatkan dua merek lipstik yang teridentifikasi positif rhodamin B yaitu lipstik I dengan $\mathrm{Rf} 0,78$ dan lipstik $L$ dengan nilai $R f 0,77$. Penentuan kadar rhodamin $B$ dari masing-masing lipstik didapatkan kadar sebesar 73,225 $\mu \mathrm{g} / \mathrm{g}$ pada lipstik I dan 92,61 $\mathrm{g} / \mathrm{g}$ pada lipstik L.
\end{abstract}

Kata kunci: kromatografi lapis tipis, kualitatif-kuantitatif, lipstik, rhodamin B, spektrofotometri UV-visibel.

\begin{abstract}
Rhodamine $B$ is synthetic dye, which its use as a coloring agent in lipstick preparation is banned as it is carcinogenic and may cause liver damages. The aim of this study is to determine rhodamine $B$ in imported lipstick preparations distributed in Batam. The methods used are thin layer chromatography (TLC) to qualitatively detected rhodamine $B$
\end{abstract}


and UV-visible spectrophotometry to quantitatively analyze the compound at a maximum wavelength of $548.5 \mathrm{~nm}$. The standard solutions of rhodamine $B$ were prepared in concentrations of $0.8,1.2,1.6,2.0$, and $2.4 \mu \mathrm{g} / \mathrm{mL}$, which generates the curve with equation of $y=0.0128+0.276 x, r=0.9999$. Rhodamine $B$ is detected in two of 15 lipstick samples, i.e., lipstick I and $L$ with $R f$ value of 0.78 and 0.77 , respectively. The respective level of rhodamine $B$ in lipstick I and $L$ is $73.22592 .61 \mu \mathrm{g} / \mathrm{g}$.

Key words: lipstick, rhodamine B, qualitative-quantitative, thin layer chromatography, UV-Vis spectrophotometry.

\section{Pendahuluan}

Lipstik telah menjadi kebutuhan pokok bagi setiap perempuan. Tujuan penggunaan lipstik bagi perempuan adalah memperindah wajah dan memberikan rona yang sehat pada wajah. Lipstik adalah sediaan kosmetika yang sudah dikenal sejak zaman peradaban manusia purba. Warna yang sering digunakan adalah warna merah dan warna merah keunguan (Heusèle et al., 2010). Sampai saat ini, lipstik dengan warna merah dan warna-warna turunannya tetap menjadi pilihan utama para perempuan.

Lipstik merupakan kosmetik dekoratif yang penggunaannya hanya untuk alasan psikologis dan persyaratan kosmetika dekoratif khususnya lipstik adalah warna yang menarik, tidak lengket, dan tidak menyebabkan iritasi pada kulit bibir (Tranggono, 2007). Sebagai kosmetika dekoratif, zat warna merupakan formula esensial dalam sediaan lipstik. Pemilihan sumber warna tersebut diharuskan memiliki kriteria aman di kulit bibir dan aman apabila tertelan ketika sedang makan (BPOM RI, 2015). Namun, penggunaan zat warna pada lipstik masih disalahgunakan dengan alasan untuk menarik konsumen dan keuntungan yang banyak. Salah satu zat warna sintesis yang sering disalahgunakan dalam pewarna lipstik adalah rhodamin $\mathrm{B}$.

Rhodamin B adalah zat pewarna sintetis yang sering disalahgunakan pemanfaatannya dalam produk kosmetika. Secara umum zat warna tersebut berupa kristal yang tidak berbau, berwarna hijau atau ungu kemerahan, dan dalam bentuk larutan berwarna merah terang dan berfluoresensi. Pewarna rhodamin B memiliki sifat toksik dan mudah larut dalam air, metanol, dan etanol (Gresshma dan Paul, 2012). Dari hasil data laporan International Agency for Research on Cancer (IARC, 1978) pada hewan uji yang diberikan rhodamin B secara subkutan dan oral menunjukkan adanya sifat karsinogenik dari zat warna tersebut. Efek yang membahayakan lainnya adalah dapat menyebabkan iritasi pada jaringan mukosa.

Telah banyak penelitian terkait analisis kualitatif dan kuantitatif senyawa rhodamin B pada sediaan lipstik yang sudah dilaporkan di beberapa kota lain dengan metode kromatografi lapis 
tipis. Hasil positif ditandai dengan adanya bercak merah muda cerah. Pada metode spektrofotometri UV-visibel, untuk analisis digunakan panjang gelombang 400-800 nm (Mukaromah dan Maharani, 2008; Jusnita dan Nandu, 2016; Yantih dan Lestari, 2012; Mamoto dan Citraningtyas, 2013). Namun, belum ada ditemukan penelitian tentang analisis sediaan lipstik impor yang beredar di Kota Batam. Dalam penelitian ini, metode yang digunakan adalah metode kromatografi lapis tipis untuk mengetahui keberadaan senyawa rhodamin B dalam sediaan lipstik impor dan metode spektrofotometri UV-visibel untuk menghitung kadar rhodamin B yang terkandung dalam sediaan lipstik impor.

\section{Metode Penelitian}

Bahan dan Alat

Bahan-bahan yang digunakan dalam peneitian ini antara lain sampel lipstik impor yang diambil secara acak, rhodamin B (Tatarasa Primatama), etanol (Brataco $\left.{ }^{\circ}\right)$, akuades, etil asetat (Aneka Kimia), amoniak (Aneka Kimia), asam klorida (Aneka Kimia), natrium sulfat anhidrat (Merck ${ }^{\circ}$ ). Sedangkan alatalat yang digunakan antara lain spektrofotometer UV-visibel (Shimadzu UV 1800), plat KLT silica gel (Merck'), timbangan analitik (Kenko ${ }^{\circ}$ ), gelas ukur (Iwaki ), labu ukur (Iwaki ), lampu UV, chamber, water bath, batang pengaduk, kaca arloji, corong, kertas saring, pipet volume, dan pipet tetes.

Jalannya Penelitian

1. Pembuatan larutan uji
Larutan uji dibuat dengan cara melelehkan 500 mg sampel lipstik, 4 tetes $\mathrm{HCl} 4 \mathrm{M}$, dan $5 \mathrm{~mL}$ etanol di atas penangas air. Selanjutnya ekstrak etanol dipisahkan dengan kertas saring yang berisi natrium sulfat anhidrat dan dimasukkan filtrat ke dalam labu ukur $25 \mathrm{~mL}$, dihomogenkan dengan sedikit etanol $70 \%$ dan ditambahkan kembali sampai dengan tanda batas.

2. Pembuatan larutan induk

Sejumlah $10 \mathrm{mg}$ pewarna rhodamin B baku dilarutkan dalam labu ukur $100 \mathrm{~mL}$ dengan etanol 70\% sampai dengan tanda batas. Larutan dikocok secara homogen (100 $\mu \mathrm{g} / \mathrm{mL}$ ).

3. Penentuan kondisi optimum

Pemilihan fase gerak dilakukan untuk memperoleh kromatografi dengan bercak yang bundar, tidak melebar, dan tidak berekor. Optimasi dilakukan dengan menotolkan bercak larutan pembanding rhodamin B kemudian dielusi dengan berbagai fase gerak, yaitu etanol 70\% : amonia (15: 5), etanol 70\% : amonia (17: 3), etanol 70\% : amonia (19:1), dan etil asetat : etanol $70 \%$ : amonia $(12,5: 5$ $: 2,5)$.

4. Analisis kualitatif

Plat KLT berukuran $10 \times 10 \mathrm{~cm}$ diaktifkan dengan cara dipanaskan di dalam oven pada suhu $100{ }^{\circ} \mathrm{C}$ selama 30 menit. Larutan uji dan larutan baku ditotolkan dengan pipa kapiler pada jarak $1 \mathrm{~cm}$ dari bawah bagian plat. Jarak antara noda adalah $1,5 \mathrm{~cm}$. Kemudian plat dibiarkan beberapa 
saat hingga mengering. Plat KLT yang telah mengandung cuplikan dimasukkan ke dalam bejana yang terlebih dahulu telah dijenuhkan dengan fase gerak terpilih. Plat dibiarkan hingga terelusi sempurna, kemudian diangkat dan dikeringkan pada suhu ruang. Warna secara visual dan warna di bawah sinar lampu ultraviolet diamati, jika secara visual noda berwarna merah jambu dan di bawah sinar lampu ultraviolet berfluorosensi merah muda atau jingga, hal ini menunjukkan adanya zat warna rhodamin B. Nilai Rf dihitung.

5. Penentuan $\lambda$ maksimum

Penentuan panjang gelombang maksimum dilakukan menggunakan spektrofotometer UV-Vis. Serapan maksimum diukur dengan rentang panjang gelombang 400-800 nm terhadap larutan baku $10 \mu \mathrm{g} / \mathrm{mL}$. Larutan blangko yang digunakan adalah etanol $70 \%$

6. Persamaan kurva baku

Penentuan kurva baku dilakukan dengan mengukur seri konsentrasi larutan baku standar, yaitu 0,8; 1,2; 1,6; 2,0; dan 2,4 $\mu \mathrm{g} / \mathrm{mL}$. Pada masingmasing konsentrasi dilakukan pengukuran serapan dengan menggunakan panjang gelombang serapan maksimum.

7. Analisis kuantitatif

Sampel yang teridentifikasi mengandung rhodamin $B$, diambil sebanyak $500 \mathrm{mg}$, ditambahkan 4 tetes $\mathrm{HCl} 4 \mathrm{M}$ dan $5 \mathrm{~mL}$ etanol $70 \%$. Campuran bahan dilelehkan di atas penangas air. Ekstrak etanol dipisahkan dengan kertas saring yang telah berisikan natrium sulfat anhidrat dan dimasukkan filtrat ke dalam labu ukur $25 \mathrm{~mL}$, dihomogenkan dengan sedikit etanol 70\%, dan ditambahkan kembali sampai dengan tanda batas. Larutan tersebut diukur dengan spektrofotometer UV-Vis pada panjang gelombang maksimum. Pengulangan perlakukan dilakukan sebanyak tiga kali dan dihitung kadar total rhodamin $\mathrm{B}$.

\section{Hasil dan Pembahasan}

Penelitian ini mengidentifikasi sediaan lipstik impor yang banyak beredar di tempat perbelanjaan di Kota Batam. Adapun perhatian peneliti dalam memilih bahan penelitian tersebut adalah banyaknya beredar lipstik impor tersebut di Kota Batam dengan harga yang tidak sesuai antara harga pasar dengan harga yang dipasangkan langsung oleh produsen produk tersebut.

Lipstik merupakan kosmetika dekoratif yang alasan penggunaannya hanyalah untuk psikologis dan dipakaikan di area wajah yaitu bibir. Maka syarat yang harus dipenuhi oleh sebuah produk lipstik tersebut adalah tidak boleh lengket dan tidak menyebabkan iritasi pada kulit bibir (Tranggono, 2007). Pengambilan sampel lipstik dilakukan dengan cara random sampling, diambil secara acak di tempat perbelanjaan yang banyak menjual produk lipstik impor dan merek yang 
berbeda-beda. Sehingga didapatkan 15 sampel lipstik yang diberi kode abjad pada masing-masing lipstik tersebut.

Pada analisis kualitatif, larutan uji sampel lipstik ditotolkan di atas plat KLT dan dibandingkan dengan larutan pembanding yaitu rhodamin B baku. Fase gerak dalam analisis KLT ini menggunakan empat jenis pelarut campuran. Dari keempat pelarut tersebut dipilih yang dapat menghasilkan bercak yang bulat, tidak melebar, dan tidak berekor. Dari keempat pelarut campuran tersebut didapatkan campuran pelarut etil asetat : etanol 70\% : amoniak dengan perbandingan $12,5: 5: 2,5$ yang merupakan campuran larutan yang dapat mengelusi zat rhodamin B secara optimum. Kondisi fase gerak yang optimum ditentukan dari nilai $\mathrm{Rf}$ yang memenuhi range nilai $\mathrm{Rf}$ yang baik yaitu $0,2-0,8$ dan lama pengembangan lebih kurang 30 menit, serta menghasilkan noda bercak yang bundar dan tidak melebar maupun berekor (Ananda et al., 2014).

Nilai Rf rata-rata yang didapatkan untuk larutan baku rhodamin B adalah 0,77-0,81. Perbedaan pada nilai $\mathrm{Rf}$ baku pembanding terjadi karena elusi noda dilakukan pada wadah yang berbeda, sehingga kondisi jenuh di dalam wadah terganggu dan menyebabkan jarak yang dihasilkan masing-masing plat KLT berbeda-beda. Sampel lipstik yang positif mengandung rhodamin B yaitu pada lipstik I dan lipstik $\mathrm{L}$ berturut-turut memiliki nilai $\mathrm{Rf}$ sebesar 0,78 dan 0,77 (Gambar 1).
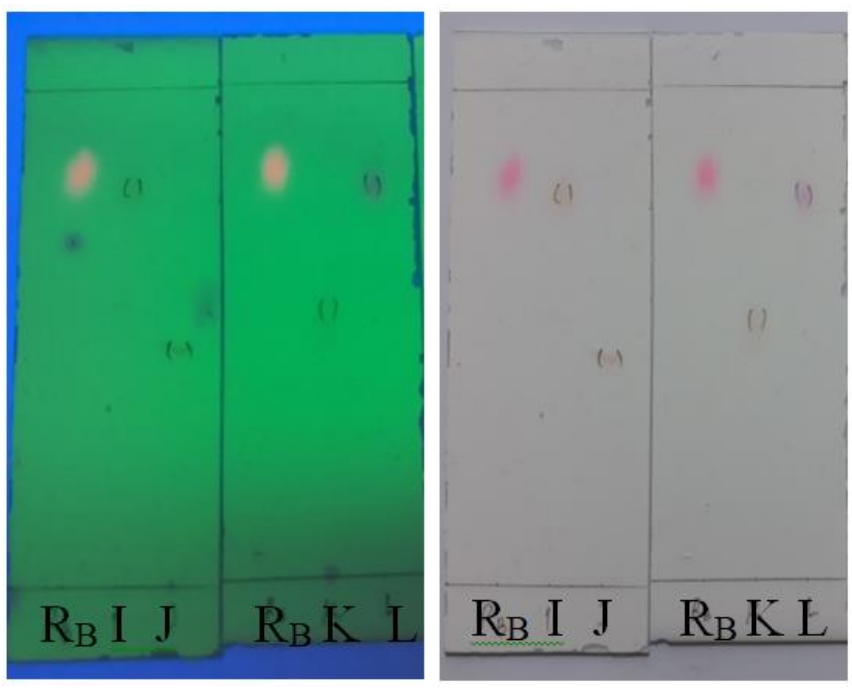

Gambar 1. Hasil analisis kualitatif dengan metode KLT. $\mathrm{R}_{\mathrm{B}}=$ rhodamin B; I, J, K, L = sampel lipstik. 
Metode spektrofotometri UV- konsentrasi bertingkat untuk visibel merupakan metode analisis yang didasarkan pada absorpsi radiasi menentukan linearitas larutan baku elektromagnetik. Metode tersebut melalui persamaan garis lurus. mengukur energi molekul dengan cara ditransmisikan, direfleksikan, atau diemisikan dalam bentuk panjang gelombang (Khopkar, 2008).

Hasil yang ditunjukkan pada analisis kuantitatif rhodamin B, panjang gelombang maksimum yang dihasilkan dari pengukuran larutan baku $20 \mu \mathrm{g} / \mathrm{mL}$ dengan jarak gelombang sinar visibel 400-800 nm adalah 548,5 nm. Dari larutan baku tersebut dibuat seri Parameter hubungan kelinieran yang digunakan yaitu koefisien korelasi $(r)$ dan koefisien determinasi pada analisis regresi linier $y=a+b x$ (Riyanto, 2014). Koefisien korelasi yang diperoleh dari seri konsentrasi rhodamin B baku adalah 0,9999 dengan persamaan linier $y=0,0128+0,276 x$. Nilai koefisien $r$ yang hampir mendekati satu menyatakan hubungan yang linear antara konsentrasi rhodamin B dengan absorbansi yang dihasilkan (Gambar 2).
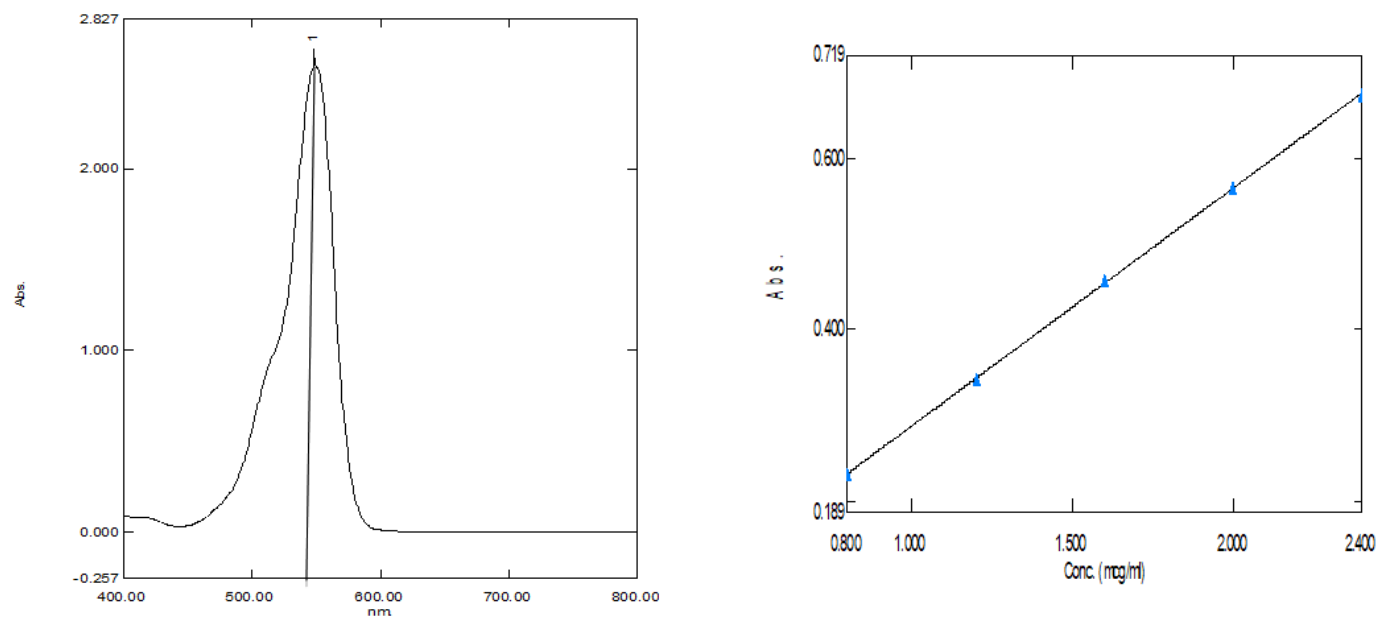

Gambar 2. Hasil spektrum $\lambda$ max larutan rhodamin B (kiri), kurva baku (kanan).

Hasil penetapan kadar rhodamin B pada sampel lipstik impor pada sampel I dan sampel L berturut-turut adalah $73,22 \pm 0,67$ dan $92,61 \pm 1,02 \mu \mathrm{g} / \mathrm{g}$. Hasil tersebut mempertegas bahwa sampel I dan sampel $\mathrm{L}$ terbukti mengandung rhodamin B. Penggunaan lipstik yang mengandung rhodamin B dalam frekuensi yang tinggi, akan terakumulasi di dalam tubuh. Dampaknya dapat berupa iritasi pada kulit dan saluran mukosa pencernaan, serta dapat menyebabkan gangguan fungsi hati atau kanker hati (Mukaromah dan Maharani, 
2008). Oleh karena itu, Badan POM telah melarang penggunaan rhodamin B pada sediaan kosmetika sesuai dengan Permenkes RI No. 239/MenKes/Per/V/85 (Bidang Informasi Keracunan-Pusat Informasi Obat dan Makanan BPOM RI, 2014).

\section{Simpulan}

Analisis rhodamin B pada 15 merek lipstik impor yang beredar di Kota Batam teridentifikasi 2 merek lipstik yang positif, yaitu lipstik I dan lipstik L. Penentuan kadar rhodamin B dengan metode spektrofotometri UV-Vis untuk lipstik I sebesar 73,225 $\mu \mathrm{g} / \mathrm{g}$ dan lipstik L sebesar $92,61 \mu \mathrm{g} / \mathrm{g}$.

\section{Daftar Pustaka}

Ananda, W.R., Kristiningrum, N., Retnaningtyas, Y. 2014. Validasi dan penetapan kadar rhodamin B pada lipstik yang beredar di sekitar Universitas Jember dengan metode KLTdensitometri. e-Jurnal Pustaka Kesehatan, 2(1):105-110.

Permenkes RI No. 239/MenKes/Per/V/85 tentang Zat Warna Tertentu yang Dinyatakan sebagai Bahan Berbahaya. Jakarta: Menteri Kesehatan RI.

Bidang Informasi Keracunan-Pusat Informasi Obat dan Makanan BPOM RI. 2014. Topik sajian utama: penggunaan rhodamin $b$ pada kosmetik. InfoPOM, 15(4):3-4.

BPOM RI (2015). PerkaBPOM RI No. 18 tentang Persyaratan Teknis
Bahan Kosmetika. Jakarta: BPOM RI.

Gresshma, R. dan Paul, M.P.R. 2012. Qualitative and quantitative detection of rhodamine $B$ extracted from different food items using visible spectrophotometry. Malaysian Journal of Forensic Sciences, 3(1):36-40.

Heusèle, C., Cantin, H., Bontè, F. 2010. Lips and lipstick. Di dalam Cosmetic Dermatology: Products and Procedures. Editor Draelos, Z.D. West Sussex: Blackwell Publishing Ltd.

International Agency for Research on Cancer. 1978. IARC Monographs on The Evaluation of Carsinogenic Risk to Humans. volume $16 . \quad$ sumber: http://monographs.iarc.fr/ENG/ Monographs/vol1-

42/mono16.pdf. Data diakses pada tanggal 12 Desember 2017.

Jusnita, N. dan Nandu, L. 2016. Identifikasi rhodamin B pada sediaan lipstik yang beredar di Pasar Jakarta Utara dengan Metode Kromatografi Lapis Tipis. Indonesia Natural Research Pharmaceutical Journal, 1(2):1-9.

Khopkar, S.M. 2008. Konsep Dasar Kimia Analitik. Jakarta: UI Press.

Mamoto, L.V. dan Citraningtyas, F.G. 2013. Analisis rhodamin B pada lipstik yang beredar di Pasar Kota Manado. Jurnal IImiah Farmasi, 2(2):61-67. 
Mukaromah, A.H. dan Maharani, E.T. 2008. Identifikasi zat warna rhodamin B pada lipstik berwarna merah. Kesehatan, 1(1):34-40.

Riyanto. 2014. Validasi dan Verifikasi Metode Uji: Sesuai dengan Iso/lec17025 Laboratorium Pengujian dan Kalibrasi. Edisi 1. Yogyakarta: Deepublish Publisher.
Tranggono. 2007. Buku Pegangan IImu Pengantar Kosmetik. Jakarta: PT. Gramedia Pustaka Utama.

Yantih, N. dan Lestari, D.A. 2012. Validation of visible spectrophotometry for determination of rhodamine $B$ in lipstick. Prosiding $24^{\text {th }}$ FAPA Congress. $13-16^{\text {th }}$ September 2012, Bali-Indonesia. 